\title{
el trabajo social EN LA RED DE ORIENTACIÓN EDUCATIVA
}

\section{Dolores Fernández Fernández}

Trabajadora social, socióloga y antropóloga. EOEP Moratalaz-Villa de Vallecas

Profesora colaboradora. Universidad Pontificia Comillas

dfernandez@upcomillas.es

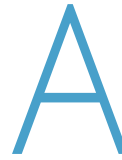

ntes de concretar la estructura organizativa que, en el momento actual, conforma la red de orientación, consideramos relevante señalar el momento en que el perfil profesional — trabajador social— se incorpora a la educación formal, concretamente al Sistema Educativo español.

Remontándonos a la breve historia, encontramos que es en los años 80 cuando los trabajadores sociales empiezan a ser contratados por el Ministerio de Educación, en el año 1980 de forma experimental y, en el año 1982, a nivel general y para el conjunto de las provincias. Esta contratación la realiza el entonces Instituto Nacional de Educación Especial (INEE), organismo autónomo ligado al Ministerio de Educación, para cubrir las vacantes que iban surgiendo con la creación de los equipos multiprofesionales, cuyo objetivo fundamental se centraba en la atención a la población de educación especial, coincidiendo con el momento en que se iba consiguiendo que todos los alumnos — también los de educación especial- dispusieran de una plaza escolar y educativa.

Será en el periodo comprendido entre 1985 y 1990 cuando se registra un gran desarrollo normativo en la educación especial empezando a funcionar el programa de integración para este alumnado.

En esas fechas se daba la convivencia en el propio Sistema Educativo de dos tipos de recursos o servicios, los de nueva creación equipos multiprofesionales (EEMM) externos al sistema, y los servicios de orientación escolar y vocacional (SOEV) cuyos componentes ya estaban en el mismo, en todos los casos eran profesores de enseñanza básica que habían cursado otros estudios.

Es en el año 1990, con la aprobación de la Ley Orgánica de Ordenación General del Sistema Educativo (LOGSE), y la posterior Orden de 9 de diciembre de 1992, es cuando se crea y regula la composición, estructura y funcionamiento de los nuevos equipos. Unificándose ambos en los actuales equipos de orientación educativa y psicopedagógica (EOEP).

Sería en el año 1993, al establecerse el procedimiento de funcionarización del personal laboral de la administración del estado, cuando los trabajadores sociales del Sistema Educativo, así como otros profesionales, pasan a ser personal docente, en concreto, los trabajadores sociales, profesores técnicos de formación profesional en la especialidad de servicios a la comunidad (PTSC).

Este hecho supuso que, a partir de ese momento, la única forma de acceder a la red de orientación educativa fuera este procedimiento, pero tuvo otras muchas consecuencias:

- La pérdida de la identidad del rol y papel profesional, todavía en desarrollo y escasamente implantado.

- Desaparecía, también, la referencia del perfil profesional para la población en general, especialmente para las familias del alumnado concreto a las que se atendía prioritariamente.

- Lo que consideramos más importante, se modificó la cualidad de las intervenciones, dejando de ser las mismas "intervenciones sociales especializadas".

El conjunto de la trayectoria permite señalar que el trabajo social se incorporó al Sistema Educativo por y para, inicialmente, la educación especial con unas atribuciones y funciones claramente definidas en el Plan Nacional de Educación Especial que se había concretado en el año 1978, con la petición-encargo de ser el elemento de conexión con el todavía escasamente desarrollado sistema de protección y de recursos para la infancia y adolescencia.

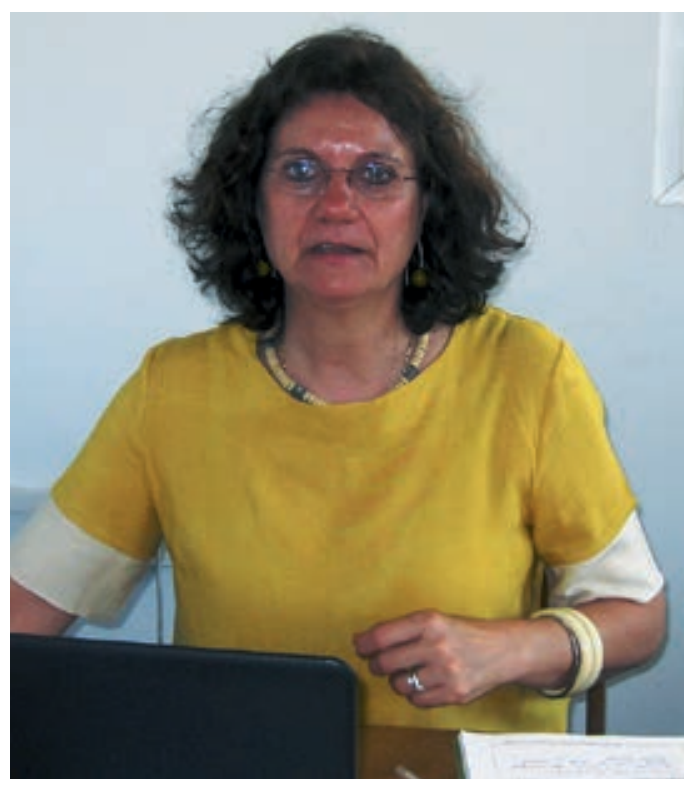

Dolores Fernández Fernández. 


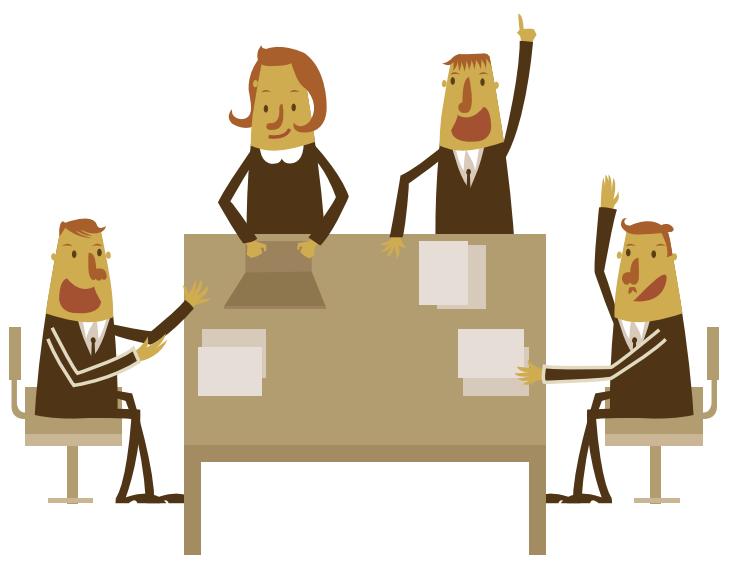

Pero es importante señalar, también, que en ese momento, el año 1993, la sociedad española, no aprovechó la oportunidad de establecer y consolidar las intervenciones sociales especializadas que venían desarrollando los trabajadores sociales en el Sistema Educativo y, con ello, se perdió la oportunidad de dar respuesta a la infancia en su conjunto, ya que al ser la enseñanza obligatoria, los centros educativos pasaban a ser un espacio privilegiado para la detección de todo tipo de situaciones.

Desde entonces y con alguna modificación la red de orientación educativa la componen:

- Los equipos de orientación educativa y psicopedagógica de atención temprana (EAT).

- Los equipos de orientación educativa y psicopedagógica (EOEP), generales de sector.

- Los EOEP específicos que atienden a la población con dificultades sensoriales como alumnado con déficit auditivo o con déficit visual, a alumnado con dificultades motoras y a los que presentan trastornos generalizados del desarrollo (TGD).

- Los departamentos de orientación (DO) de los institutos de enseñanza secundaria (IES) y/o de los centros de educación especial (CEE).

Estos recursos del sistema educativo están compuestos por profesionales de diferentes perfiles que, en el momento actual son, fundamentalmente psicólogos o pedagogos o psicopedagogos convertidos en profesores de psicopedagogía, hoy llamados orientadores, y los ya mencionados profesores técnicos de formación profesional (PTSC). Tienen carácter interdisciplinar, por lo que la tarea —siempre que el número de efectivos lo permite- lo es en equipo e interdisciplinarmente $y$, necesariamente, en coordinación con los diferentes recursos y servicios del sector geográfico de actuación que, en la Comunidad de Madrid, para los diferentes equipos coincide con los distritos municipales o municipios y localidades.

Las intervenciones están dirigidas, fundamentalmente aunque no exclusivamente, a la población en edad de enseñanza obligatoria residente y/o escolarizada en un área geográfica de actuación concreta que, en la Comunidad de Madrid y en la territorial de Madrid capital, desde hace varios años, estos espacios geográficos de actuación los componen, a nivel general y para cada uno de los servicios o equipos generales de sector, al menos, dos distritos municipales.
Las funciones atribuidas a los EOEP son, entre otras:

- La intervención con alumnos - fundamentalmentepara valorar y determinar las necesidades educativas que presenten.

- La intervención con los profesionales docentes para orientar y asesorar su trabajo con determinados alumnos o grupos de alumnos.

- Las intervenciones con las familias de este alumnado o de otro, para valorar la situación sociofamiliar, sus condiciones de vida, orientar y/o asesorar para favorecer el desarrollo armónico del alumno/s y/o para plantear una derivación a otros servicios complementarios.

- La coordinación con otros recursos y servicios del sector educativo en el que se interviene, especialmente con todos aquellos que atienden a la infancia y sus familias.

Es importante señalar que, dependiendo del número de efectivos que componen cada equipo o departamento de orientación, va a ser posible incidir en mayor o menor medida en un ámbito de actuación o en otro, o más con los alumnos o sólo con los alumnos, o también con el profesorado, con las familias, etcétera.

Lo relevante, en el momento actual y desde hace algunos años es que las plantillas están estancadas o se van reduciendo progresivamente, independientemente del volumen de población que va llegando a cada espacio geográfico o a cada centro educativo, instituto, centro de educación especial, escuela infantil, etéctera.

Unido a esta progresiva reducción del número de efectivos, el perfil profesional responsable o más dedicado a la intervención social como son los profesores técnicos de formación profesional de la especialidad Servicios a la Comunidad, están escasamente representados en estas estructuras o recursos de las consejerías de educación, por lo que ven limitadas las posibilidades de actuación, no pudiendo en ocasiones incidir o intervenir en diferentes casos individuales en los que sería necesario hacerlo o en centros educativos con necesidades de intervención a todos los niveles y/o en situaciones de algunos menores-alumnos y sus unidades familiares por los riesgos que representan sus características y/o condiciones de vida.

Esta realidad determina que, en los últimos años, se estén limitando un conjunto de actuaciones que, en equipo y a nivel interdisciplinar se venían realizando con un carácter claramente preventivo, como son todas las intervenciones indicadas cuando se detectan cualquier circunstancia que compromete el desarrollo armónico y progresivo de cualquier menor/alumno.

Consideramos importante, también, poder destacar los aspectos más positivos que representa esta red de orientación educativa ya que incide en situaciones de la vida escolar del alumnado, de sus familias y profesores. Triada en la que siempre estará en juego o comprometido la vida de la infancia-alumnos, su progreso, desarrollo, su futuro inmediato o a medio y largo plazo. Sus posibilidades de éxito o de fracaso. En definitiva "la construcción" de una persona. 
Igualmente consideramos que es importante destacar que los EOEP, al ser una estructura externa a los centros escolares, si contaran con suficiente número de efectivos como para poder dar respuestas a sus diferentes ámbitos de actuación, podrían realizar múltiples actuaciones, tomando decisiones determinantes para la infancia-alumnos y realizar en equipo - con el enriquecimiento que esto supone- el conjunto de su trabajo del que siempre se verían beneficiados los centros educativos.

A la vez, la condición de ser responsables de un sector educativo les permite conocer un entorno escolar complejo, identificar necesidades de la población en edad de enseñanza obligatoria en general $y$, en esa medida, realizar las intervenciones y propuestas necesarias que permitan modificar o mejorar las situaciones conocidas y detectadas.

En la práctica, los recursos del Sistema Educativo externos a los centros escolares, los EOEP, en los últimos años, vienen centrando sus actuaciones por prescripción administrativa en la atención al alumnado que presenta necesidades educativas específicas, según la Ley Orgánica de Educación (LOE) del año 2006, más concretamente y preferentemente por la escasa disponibilidad de efectivos, en los alumnos con necesidades educativas especiales (acnee) y en la población escolar que presenta situación de desventaja social, el alumnado conocido como de compensación educativa.

Además, estos equipos, simultáneamente intentan profundizar en algunas temáticas que siéndoles propias y características de sus funciones, en algunos momentos adquieren carácter de dificultad para la comunidad educativa en su conjunto, como pueden ser entre otros temas, los trastorno específicos del lenguaje (TEL), la problemática de aprendizaje de algunos alumnos. El asesoramiento y orientaciones en general y en particular a la población con altas capacidades o sobredotación, los deberes escolares y su incidencia en la vida de los alumnos y familias.

Por ello, el conjunto de artículos que se presentan a continuación intentan ser una muestra de los diferentes ámbitos de intervención social especializada — desde la perspectiva del trabajo social- aunque no sólo, ya que no siempre es posible incidir en los distintos ámbitos y, no siempre los profesionales cuentan con la formación específica del perfil profesional trabajador social.

El primer artículo refleja la intervención social especializada en un centro de educación especial concreto que reúne características propias, como es contar con plazas de residencia-internado y escolarizar a población con discapacidad motora.

El segundo artículo se centra en los deberes escolares, desde la perspectiva de la investigación acción, realizada en un amplio periodo de trabajo desde un equipo general de sector. El tercero incide en el asesoramiento y orientación a una tipología específica de alumnado en el que la triada que representa la comunidad escolar adquiere un gran protagonismo. El cuarto se dirige a la concreción de la intervención social en un instituto de enseñanza secundaria.

Además de los artículos, se presentan dos experiencias, una realizada en un colegio público a iniciativa de los docentes del propio centro, en el que lo destacable es comprobar cómo se puede conjugar el aprendizaje académico con la educación globalmente considerada, siendo muy relevante conocer las oportunidades que se les ofrecieron a un grupo de alumnos, de obtener experiencias de éxito, así como el cuidado personal que se ofrece a los mismos al estar este componente implícito en la propia experiencia.

En la segunda experiencia que, a nivel general, viene definida por la administración educativa, lo relevante es comprobar la no presencia ni la atención del profesional especialista de la intervención social, en centros que escolarizan preferentemente a una tipología determinada de alumnado, como es, en este caso, los centros que integran preferentemente a alumnado con trastornos generalizados del desarrollo (TGD).

\section{Para saber más}

- Burudy, J., y Dantagnan M. (2005). Los buenos tratos a la infancia. Parentalidad, apego y resiliencia. Barcelona: Gedisa.

- Dubet, F. (2005). La escuela de las oportunidades. ¿Qué es una escuela justa? Barcelona: Gedisa.

- Jociles, Ma I.; Franzé A., y Poveda, D. (eds.) (20II). Etnografías de la Infancia y de la adolescencia. Madrid: Catarata.

- Monix Martínez, M. (2006). Teoría del trabajo Social. Madrid: Síntesis.

- Importante también poder acceder a las diferentes publicaciones periódicas de los colegios profesionales, el Consejo General de Trabajo Social y de las universidades como, por ejemplo los Cuadernos de Trabajo Social de la Universidad Complutense de Madrid, ya que recogen las temáticas actualizadas y más relevantes en cada momento de la disciplina del trabajo social.

\section{hemos hablado de:}

\section{Red de orientación educativa, espacio geográfico de actuación, intervención social especializada en el ámbito educativo.}

Este artículo fue solicitado por PADRES Y MAESTROS en enero de 2014, revisado y aceptado en abril de 2014 para su publicación.

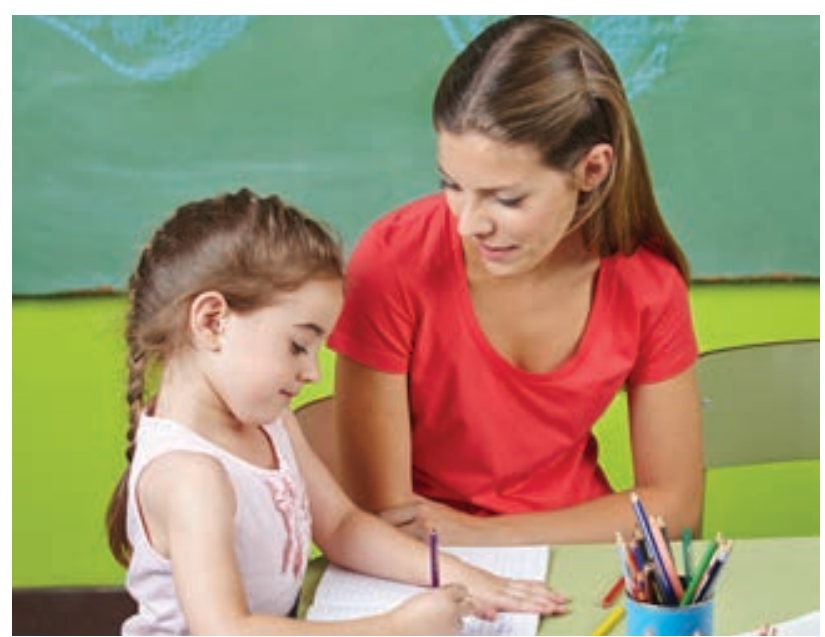

